\title{
4th ventricular ependymoma with lumbosacral metastasis surgically removed at one sitting: a case report
}

\begin{abstract}
An ependymoma is a glial tumor of the ependymal cells that line the center of the spinal cord and the ventricles of the brain. Ependymomas are physically soft, have a gray or red color, and may contain mineral calcifications or cysts within them. A tumor can occur anywhere where ependymal cells are present in the central nervous system. Ependymoma cancer is rare. It occurs in both children and adults, and in men and women relatively equally. However, ependymomas are more common in children than in adults. Here with we report a $24 \mathrm{yr}$ old lady with posterior fossa ependymoma with spinal metastasis managed by single sitting with good post operative outcome.
\end{abstract}

Volume 9 Issue $3-2019$

\begin{abstract}
Ahmed Alazry, Sharad Samson Rajmani, Neeraj Salhotra, Bashar AI Tunbi, Samit Biniwale, Marwa S.Al Daihani

Department of neurosurgery, Khoula hospital, Oman
\end{abstract}

Correspondence: Neeraj Salhotra, Department of neurosurgery, Khoula hospital, Muscat, Oman, Tel 0096895394198, Email neersal@hotmail.com

Received: May 13, 2019| Published: May 20, 2019

\section{Introduction}

Ependymoma is a type of tumor that can form in the brain or spinal cord. Ependymoma begins in the ependymal cells in the brain and spinal cord that line the passageways where the fluid (cerebrospinal fluid) that nourishes your brain flows. Ependymoma can occur at any age, but most often occurs in young children. Children with ependymoma may experience headaches and seizures. Ependymoma that occurs in adults is more likely to form in the spinal cord and may cause weakness in the part of the body controlled by the nerves that are affected by the tumor. Surgery is the primary treatment for ependymoma. For more aggressive tumors or for tumors that can't be removed completely with surgery, additional treatments, such as radiation therapy or chemotherapy, may be recommended.

\section{Materials and methods}

A 24year old lady was admitted in our hospital with complaints of headache, ataxic gait and left lower limb numbness and dysphagia . On examination cerebellar ataxia was confirmed and she had lower cranial nerve involvement. There was no motor deficit in lower limbs except some paresthesia in left lower limb. Patient underwent MRI brain and spinal screening for any drop metastasis. MRI revealed large 4th ventricular tumour with extension via foramina of lushka and megendie to the $\mathrm{CV}$ junction region engulfing the full region causing Arnold chiarima formation. Spinal screening revealed large drop metastasis from the L3 to S2 region engulfing the spinal nerves and causing localized pressure to neural elements. ${ }^{1-6}$

\section{Results}

After through explanation to the family about the nature of disease and outcome and once family agreed patient underwent single sitting posterior fossa craniotomy and microsurgical excision of the 4th ventricular lesion with craniomedullary junction spread and then L3 to S1 laminectomy and excision of the intradural spinal metastasis. Postoperative period was uneventful. Patient was extubated on table. After $24 \mathrm{hr}$ stay in ICU was shifted to the ward. Physiotherapy and nursing care was continued. Histopathology came to be ependymoma grade II. Patient is referred to the radiation and chemotherapy department for further management and has been discharged to be followed in outpatient department after radio/chemotherapy. (Figure $1-4)$

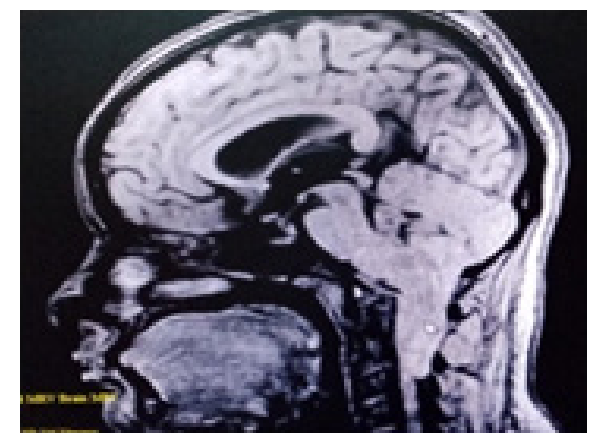

Figure I Preoperative MRI showing 4th ventricular lesion.

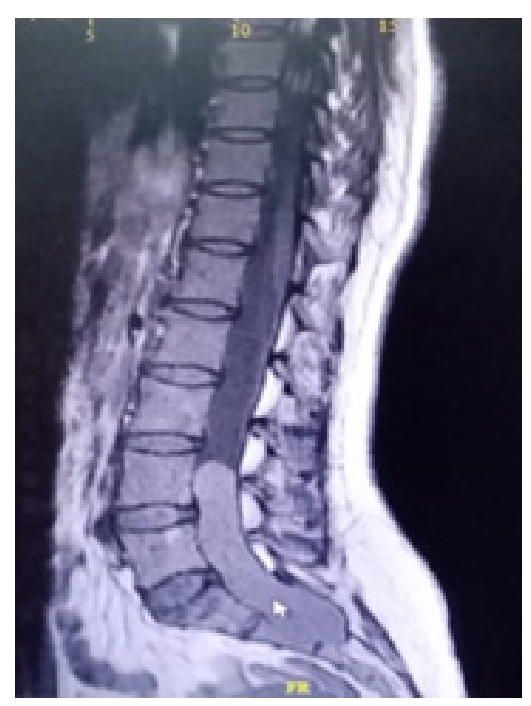

Figure 2 Preoperative MRI showing spinal lesion. 


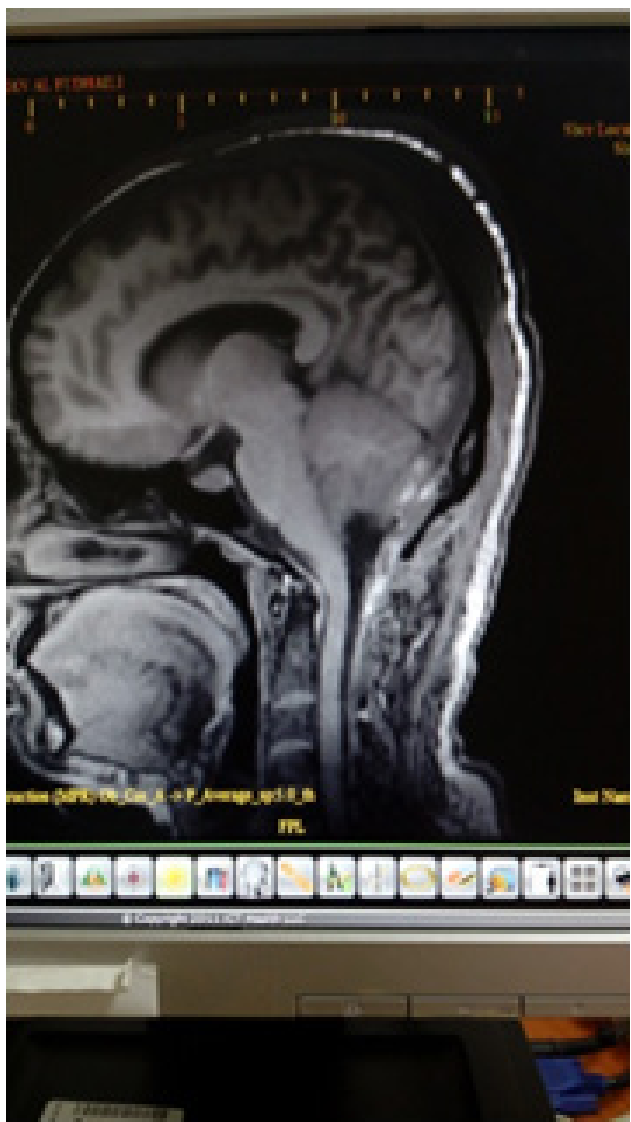

Figure 3 Postoperative MRI showing tumour excision.

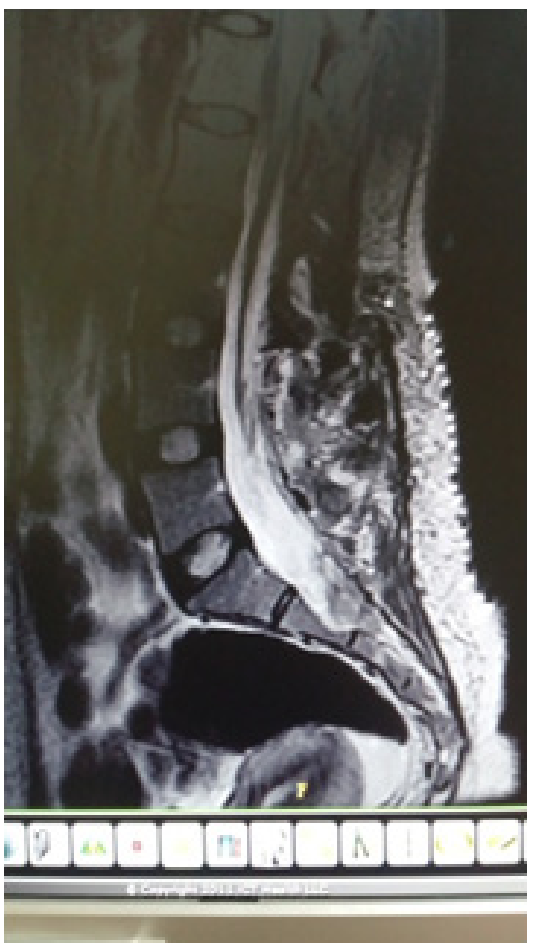

Figure 4 Postoperative MRI showing well excised spinal metastasis.

\section{Discussion}

As per Bastron $\mathrm{A}^{3}$ results support early surgery aiming at complete resection as the primary treatment for presumed spinal ependymomas. The prognosis after surgery for some myxopapillary ependymomas seems worse than generally believed. As per Lee $\mathrm{TT}^{5}$ surgical resection of spinal ependymoma leads to significant improvement of pre-operative symptoms. Surgical removal alone, with an attempt to grossly resect the tumor, should be the treatment of choice, with careful clinical and radiographic follow-up. Radiation therapy should only be considered as a surgical adjunct where gross total resection is not achieved. As per Mettelus $\mathrm{P}^{6}$ multivariate analysis retained extent of surgery, histological grade and complementary treatment as the most important predictors of progression-free survival. As per Andrade $\mathrm{FG}^{4}$ the location of the intracranial tumor is connected with the degree of resection; however it is not a predictive factor to overall survival. Use of dextroscope in preoperative planning is discussed by Anil SM. ${ }^{1}$

\section{Conclusion}

Ependymomas are common tumour seen in paediatric age group but not uncommon in adults. Our patient was a 24 year old adult with large 4 th ventricular tumour with extracranial spread in craniomedullary junction and spinal drop metastasis in lumbosacral region. Both lesions were managed in same sitting with good post operative outcome.

\section{Acknowledgments}

None.

\section{Conflicts of interest}

Author declares that there is no conflict of interest

\section{References}

1. Anil SM, Kato Y, Hayakawa M, et al. Virtual 3-dimensional preoperative planning with the dextroscope for excision of a 4th ventricular ependymoma. Minim Invasive Neurosurg. 2007;50(2):65-70.

2. Ager BJ, Christensen MT, Burt LM, et al. The value of high-dose radiotherapy in intracranial ependymoma. Pediatr Blood Cancer. 2019;66(6):e27697.

3. Boström A, von Lehe M, Hartmann W, et al. Surgery for spinal cord ependymomas: outcome and prognostic factors. Neurosurgery. 2011;68(2):302-308

4. Andrade FG, Paulo Henrique, Hamilton Matushita, et al. Intracranial and spinal ependymoma: series at Faculdade de Medicina, Universidade de São Paulo. Arq Neuropsiquiatr. 2009.

5. Lee TT, Gromelski EB, Green BA. Surgical treatment of spinal ependymoma and post-operative radiotherapy. Acta Neurochir (Wien). 1998;140(4):309-13.

6. Metellus $\mathrm{P}$, Barrie M, Figarella-Branger D, et al. Intracranial ependymomas in adult patients. Retrospective analysis of 121 cases from the multicentric. Neurochirurgie. 2007; 53(2-3 Pt 1):66-75. 